\title{
UMA PERSPECTIVA COMUNICACIONAL DA QUESTÃO DEMOCRÁTICA - TÓPICOS PARA O DEBATE SOBRE POLÍTICAS PÚBLICAS DE COMUNICAÇÃO
}

Antonio Carlos Sardinha

Jornalista diplomado, especialista em Direitos Humanos, mestre em comunicação (UNESP/SP)

\section{Resumo}

Pensar políticas de comunicação para as instituições públicas é discutir no atual cenário brasileiro e latino-americano possibilidades para posicionar de modo constitutivo a comunicação em meio às disputas por políticas públicas no cenário democrático. Nesse sentido, a associação da Comunicação Pública ao fortalecimento da participação demanda superar não só contradições da cultura democrática, mas limitações históricas e epistemológicas próprias do campo da comunicação e das políticas para essa área desenvolvidas no interior do Estado.

Palavras-chave: Comunicação pública; políticas de comunicação; democracia; participação

\begin{abstract}
Thinking communication policies for public institutions is to discuss the current Brazilianand Latin American scene possibilities of incorporation in order to place the communication in the means of disputes for public policies in the democratic scene. Accordingly, the association of Public Communication at strengthening the participation demands not only overcome the contradictions of democratic culture, but also historical and epistemological limitations inherent to thefield of communication and policies developed for that area within the State.
\end{abstract}

Keywords: Public communication; political communication; democracy; participation

\section{Resumen}

Conceptuar políticas de comunicación para instituciones públicas es discutir, en el actual escenario brasileño y latinoamericano, posibilidades para comprender el papel constituyente de la comunicación en las disputas por políticas públicas en la democracia. En esa acepción, asociar el fortalecimiento de la participación a la Comunicación Pública demanda superación no solo de contradicciones en la cultura democratica, pero también de limitaciones historicas y epistemologicas propias de la comunicación y de las políticas estatales desarrolladas en ese campo.

Palabras clave: la comunicación pública; comunicación política; la democracia; la participación

EXTRAPRENSA (USP) - Ano V - no 09

dezembro/2011 
UMA PERSPECTIVA COMUNICACIONAL DA QUESTÃO

DEMOCRÁTICA - TÓPICOS PARA O DEBATE SOBRE POLÍTICAS

PÚBLICAS DE COMUNICAÇÃO

\section{Informação, comunicação e conhecimento}

A compreensão dos fundamentos que dão sentido à Sociedade da Informação passa pela compreensão dos termos usados para nominá-la. Para Mattelart (2006), a ideia de uma sociedade regida pela informação está inscrita no código genético do projeto de sociedade inspirado pela mística do número, o que começa antes mesmo da entrada da informação na língua e cultura da modernidade. Esse projeto é anterior e começa ser organizado nos séculos XVII e XVIII com a matemática modelizando o raciocínio e a ação útil, ressoando depois nos princípios universais e no modelo de igualdade da Revolução Francesa.

As mudanças tecnológicas (sobretudo nas tecnologias da informação e comunicação) que acompanham um movimento geopolítico de controle do espaço, de avanço no jogo de forças para definir uma geopolítica atrelada a interesses econômicos e militares que acompanha o período de guerras mundiais e conflitos subsidiários (MATTELART, 2006) vão mexendo com o tecido das sociedades em um movimento rumo à reconfiguração relações econômicas, políticas e culturais.

Para Harvey (2000) o capitalismo se organiza ainda mais com a flexibilização, mobilidade no mercado de trabalho, nos processos de trabalho e no mercado de consumo que é acompanhado por pesadas doses de inovação tecnológica, de produto e institucional. Na ausência de limites sociais, físicos e de outra ordem, a economia de mercado adota uma qualidade dinâmica e expansiva, tendo como um dispositivo central a organização em rede dos processos sociais.

Nesse sentido, o valor surge da capacidade (e demanda) permanente de organizar um suposto tempo futuro. A nova economia, uma economia da atenção e da emoção, trabalha com a contraditória relação de excesso e escassez de informação como fonte de valor no jogo de acumulação.

Para Lopes (2008), há determinismo presente na concepção das TICs como meios para uma regulação econômica, com capacidade de desenvolvimento de uma economia não mercantil, de uso elevado e estratégico das capacidades cognitivas e sígnicas alterando a força e o processo de trabalho (imaterial). Essa compreensão está alicerçada na tensão permanente entre a racionalização e a racionalidade entre técnica e o mundo da vida e também no papel produtivo da comunicação (meios), da informação e da cultura diante do processo de acumulação de capital e a demanda por reprodução simbólica do mundo vivido (LOPES, 2008).

A questão central para o autor, não contemplada nas análises, é o esclarecimento das marcas distintivas, do regime de acumulação contemporâneo, isto é, a transformação

EXTRAPRENSA (USP) - Ano V - no 09

dezembro/2011 
UMA PERSPECTIVA COMUNICACIONAL DA QUESTÃO DEMOCRÁTICA - TÓPICOS PARA O DEBATE SOBRE POLÍTICAS PÚBLICAS DE COMUNICAÇÃO

da virtualidade técnica, como o desenvolvimento das TICs, em principal fato econômico, o que não confere ao sistema nova regulação, mas acirra-lhe o descontrole (LOPES, 2008, p. 23).

Nessa reacomodação do capitalismo, destaca-se ainda sua expansão para territórios ainda não plenamente apropriados e de natureza imaterial como cultura, o afeto, o bios (vida). Esse território tem os meios de comunicação como componentes importantes. As tecnologias e o arranjo que elas permitem, facilitando a flexibilização, os fluxos, a compressão espaço-tempo servem como estruturas fundamentais para o capitalismo contemporâneo, com contradições pouco ressaltadas.

O significado que a Comunicação assume em um contexto global de trocas e intercâmbio de informações é importante quando pensamos o diálogo entre práticas de comunicação em meio aos discursos da informação, do conhecimento e da ação (WOLTON, 2006) $)^{1}$, que estruturam a relação com o mundo e referenciam os sujeitos na sua busca por compreender a realidade.

Ao destacar a dimensão normativa da Comunicação, bem como destacar os seus aspectos políticos e culturais, Wolton (2006) sugere um lugar para a Comunicação. Ao invés de restringir-se à transmissão de dados, comunicar é menos um processo com começo e fim e mais uma questão de mediação, um espaço para de coabitação, um dispositivo que visa amortecer o encontro de várias lógicas que coexistem na sociedade aberta (WOLTON, 2006, p.32).

A Comunicação torna-se, nesse sentido, valor central em uma sociedade aberta que há mais de dois séculos, ao menos no Ocidente, superou a centralização e as hierarquias em favor do sujeito e de sua liberdade e onde as trocas entre os indivíduos têm um valor intrínseco. Essa dimensão normativa, em contraponto à dimensão funcional, confere à Comunicação um papel de organização simbólica, mais do que um canal, em meio à profusão técnica de transmissão de dados e informação.

Para Wolton (2006) caminha-se para uma terceira etapa da relação informaçãocomunicação em que estão colocadas as condições para garantir a dimensão normativa da comunicação, ou seja, em detrimento de aspectos técnicos e econômicos, e do fetiche da velocidade, da quantidade e da transmissão, estão os valores, a sociedade, os conflitos e a questão do sentido negociado, e não imposto.

A negociação presume a ideia da coabitação cultural, de reconhecimento do outro. Esse se torna o horizonte da comunicação e, por conseguinte, da democracia, por presumir a organização do poder e da autoridade pela negociação e pelo debate. Essa possibilidade coloca a Comunicação não como solução, mas com um problema a ser administrado e não negado. Assume-se o risco da incomunicação, das tensões e do conflito que não está

EXTRAPRENSA (USP) - Ano V - no 09 dezembro/2011 
UMA PERSPECTIVA COMUNICACIONAL DA QUESTÃO DEMOCRÁTICA - TÓPICOS PARA O DEBATE SOBRE POLÍTICAS PÚBLICAS DE COMUNICAÇÃO

previsto na exacerbação estratégica da dimensão funcional da Comunicação pelos adeptos da Sociedade da Informação.

O entendimento de que a Comunicação veicula visões da relação com o outro, ao passo que a cultura veicula visões de mundo, favorece o retorno do social entre a política e a cultura. Isso porque, ao andar de mãos dadas com a Cultura, a Comunicação faz pensar e torna-se, nas palavras de Wolton (2006), um "catalisador de conscientização".

Há uma mudança de estatuto que sinaliza a vitória da Comunicação. Menos que um dispositivo técnico, a Comunicação torna-se a condição para simbolização, que permite o funcionamento das sociedades abertas. Ganha o espaço da representação, com reforço da sua dimensão normativa. "Quanto mais a comunicação se instrumentaliza, mais ela se perde, como se finalmente o essencial não estivesse no conteúdo da troca, na intencionalidade dos atores, mas numa certa "poesia" das trocas" (WOLTON, 2006, p.141).

\section{Da sociedade dos meios à sociedade midiatizada}

Em outras palavras, estamos percebendo os fenômenos comunicacionais como um dos processos sociais da comunicação formado pelos (1) processos comunicativos que coloca em comum diferenças, por meio do discurso que tem ou não o auxílio da retórica e (2) pelos processos comunicacionais, entendidos como fenômenos constituídos pela ampliação tecnológica da retórica - a mídia na sociedade contemporânea (SODRÉ, 2007).

Nessa perspectiva, os processos comunicativos são, em linhas gerais, parte de uma ontologia constitutiva da realidade social. Mas os processos comunicacionais, pelo exposto na configuração da Sociedade da Informação, assumiram uma condição importante apresentando-se como mais um marco interpretativo.

Nesse sentido, não implica só o processo de restabelecimento de laços sociais, mas é relacionada a atos e valores. A comunicação - como práxis - deve ser o lugar de sentido e significação (VIZER, 2006, p.29).

Sodré (2006) entende que a sociedade contemporânea (dita pós-industrial) é regida pela midiatização, ou seja, virtualização das relações humanas presente nos relacionamentos institucionais e demandas individuais de conduta com as tecnologias da comunicação. "Trata-se de um dispositivo cultural historicamente emergente no momento em que o processo da comunicação é técnica e mercadologicamente redefinido pela informação, isto é, por um produto a serviço da lei estrutural do valor também conhecido como capital" (SODRÉ, 2006, p.21)

É por isso que para o autor, a midiatização não é a veiculação de acontecimentos por meios de comunicação, como se fato temporalizado precedesse o midiático, de natu-

EXTRAPRENSA (USP) - Ano V - no 09 dezembro/2011 
UMA PERSPECTIVA COMUNICACIONAL DA QUESTÃO DEMOCRÁTICA - TÓPICOS PARA O DEBATE SOBRE POLÍTICAS PÚBLICAS DE COMUNICAÇÃO

reza transtemporal. O que há é o funcionamento articulado das instituições em geral com a mídia. Ao basear-se em Foucault, Sodré (2007) define a sociedade midiatizada como um novo tipo de sociedade do discurso, conceituada como a organização de grupos constituídos em função do controle específico da fala, institucionalizando procedimentos de exclusão - interdição, rejeição e vontade da verdade que incidem sobre o discurso. Um discurso que controla a sociedade e constitui-se ele próprio uma esfera existencial particular abstrata em relação ao tempo e espaço, assim como é a língua em relação ao discurso (SODRÉ, 2007, p.20)

Nesse contexto, a comunicação para Vizer (2007) é constituinte e instituinte das relações e vínculos sociais, uma ação indicial geradora de sentido com três dimensões: referencial, interferencial e auto-referencial. A primeira atua como dispositivo de construção discursiva da realidade objetal (o conteúdo); a segunda atua na construção de relações entre os atores sociais que se referenciam mutuamente (relações e interações sociais), já a terceira refere-se a processos de auto-observação reflexiva e da apresentação de si mesmo em sociedade, são as marcas de identidade e identificação. Essa dimensão refere-se à construção social da pessoa enquanto sujeito e ator social. Com base em Vizer (2007), compreendemos que a midiatização das práticas sociais constroi comunicacionalmente os sujeitos-atores nessas três dimensões. Os meios de comunicação e as tecnologias da informação não rompem, mas ao contrário, midiatizam em novos tempos e espaços.

Fausto Neto (2008) ilustra o fenômeno da midiatização com a ideia de que as práticas discursivas de diferentes campos (políticos, econômicos, saúde, religião) transformam-se a partir da presença de complexas operações de apropriação de características midiáticas, redesenhando suas gramáticas e suas estratégias de reconhecimento. Essa forma de inscrição tecnodiscursiva das lógicas e operações das mídias alastra-se por toda a estrutura, levando para todas as instâncias societárias os fluxos e efeitos sociotécnicos caracterizados pela cultura e operações midiáticas. O campo das mídias não é protagonista, mas expande os protocolos midiáticos para o tecido de práticas sociais, fenômeno operado pela convergência tecnológica (FAUSTO NETO, 2010).

\section{Comunicação Pública e Democracia em tempos de midiatização}

O debate sobre Comunicação Pública em tempos de midiatização requer a compreensão das relações políticas entre as Sociedades e o Estado nesse cenário de desregulamentação e fluidez das redes. A questão, em uma perspectiva comunicacional, é saber como dimensionar esse cenário em que foram potencializados, de modo muito mais explícito, a relação estrutural informação-poder, ou os recursos informação-poder, como vetores para organização de práticas sociais, sobretudo políticas.

Essa dinâmica societária tem uma constituição tecnicamente concreta, mas um aspecto simbólico e ideológico que reitera, em meio ao discurso da fluidez, a idéia sobre o

EXTRAPRENSA (USP) - Ano V - no 09 dezembro/2011 
UMA PERSPECTIVA COMUNICACIONAL DA QUESTÃO DEMOCRÁTICA - TÓPICOS PARA O DEBATE SOBRE POLÍTICAS PÚBLICAS DE COMUNICAÇÃO

fim da história, da ideologia, dos projetos societários, reconfigurando assim o paradigma do conflito social e da oposição violenta, nas expressões de Vizer (2007), para explicar o cenário da década de 1990. É um período em que o conflito social se transfigura em imaginários que se tornaram parte de uma nova cultura democrática envolvendo questões sobre inclusão, integração social, pluralismo e direitos humanos, além do debate sobre minorias, identidades e diferenças, em uma perspectiva de integração a um sistema de acumulação em gestação com políticas neoliberais.

O desmonte do Estado de bem-estar social e os cortes das políticas sociais a partir da década de 1980 também parecem indicar os efeitos redistributivos da democracia que hegemonicamente predominou ao final das duas guerras mundiais - restrição das formas de participação e soberania ampliadas em favor de um consenso em torno das eleições para formar governos (SANTOS e AVRITZER, 2002).

O ressurgimento das democracias nas décadas de 1980 em muitos países da América Latina fez, segundo Vizer (2007), com que as sociedades nesses países observassem um movimento para (re)construir bases plurais das formas institucionais de um regime democrático. A demanda por reconhecimento e participação nos espaços públicos de ação e nas decisões do Estado por parte de muitos grupos e comunidades acompanham uma tendência de limitações nas democracias representativas que, se por um lado tem pela via da autorização das eleições uma via para o exercício da democracia em escala ampliada, tem dificuldade para lidar com a questão da prestação de contas e da representação de múltiplas identidades (SANTOS e AVRITZER, 2002).

No Brasil esse processo é permeado por contradições, experiências distintas e desafios próprios da cultura democrática do país. $\mathrm{O}$ autoritarismo social e visões hierárquicas e excludentes da sociedade e da política são obstáculos para constituição e funcionamento de novos espaços para participação nas decisões sobre políticas públicas, sendo a confrontação desses mesmos padrões um dos principais resultados democratizantes dos novos espaços públicos (DAGNINO, 2002).

A exposição desse cenário é importante para delinear sua relação com o movimento ainda incipiente de consolidar a Comunicação Pública enquanto modelo teóricoinstrumental do sistema político para mediar interações comunicativas entre Estado e a sociedade (MATOS, 2009)

A Comunicação Pública - que se diferencia da Comunicação Governamental -, entendida como a comunicação que ocorre no espaço formado por fluxos de informação e interação entre agentes públicos e atores sociais em temas de interesse público por meio da promoção do direito à informação e a comunicação (DUARTE, 2009), estabelece por essa via uma relação estrutural no debate sobre a democratização do Estado e na constituição de novas institucionalidades. E nessa via, que relaciona a Comunicação Pública ao exercí-

EXTRAPRENSA (USP) - Ano V - no 09 dezembro/2011 
UMA PERSPECTIVA COMUNICACIONAL DA QUESTÃO DEMOCRÁTICA - TÓPICOS PARA O DEBATE SOBRE POLÍTICAS PÚBLICAS DE COMUNICAÇÃO

cio do poder político em sociedades democráticas, que estão as possibilidades para pensar do ponto de vista teórico o escopo desse campo, ressignificando o papel da comunicação historicamente pensada no âmbito do Estado.

A Comunicação Pública estabelece relação constitutiva com a democracia, por interferir na distribuição de poder político, ao ser configurada conforme Brandão (2009), como um processo de comunicação que se estabelece em uma esfera pública entre o Estado, Governo e Sociedade para ser um espaço privilegiado de negociação para as disputas nas sociedades políticas.

A Comunicação Pública, portanto, precisa ser pensada em um diálogo afinado com as teorias democráticas pela relação das políticas de comunicação com a prática da democracia ao instituírem um dado padrão de conflitualidade na esfera pública e assim um dado modelo de democracia (PITTA, 2001).

Pensar a Comunicação Pública nos moldes democráticos, atendendo aos desafios de comunicação do Estado, sobretudo diante da demanda por participação, que também se consolidam na cena democrática, amplia o escopo de debate sobre políticas de comunicação, por duas perspectivas. Em um primeiro aspecto reposiciona a área de comunicação no conjunto das políticas públicas como serviço a ser prestado pelo Estado e de natureza fundamental para garantia do direito à comunicação e à informação - elementos centrais para pensar a consolidação da Comunicação Pública.

Sob outro aspecto, entende-se que como modelo conceitual-operativo para pensar a relação comunicativa entre o Estado e a Sociedade, a Comunicação Pública é um campo de referência para o debate sobre participação e controle social de políticas públicas, no entendimento de que a constituição dessas políticas tem um escopo comunicacional que as delineiam e as definem diante das relações de poder gestadas estruturalmente pelas ações comunicativas - sistematizadas ou não pelas instituições públicas.

Conforme apontamos em Signates (2009), não há uma articulação teórica e uma experiência prática da comunicação como política pública, somado a isso, a incipiente democracia brasileira impede que a comunicação se consolide como política de participação. No arranjo marcadamente mercantil do nosso sistema de mídias, pensar a Comunicação Pública é uma tarefa complexa não só pelos eventuais entraves conceituais, mas histórico-conjunturais de como a comunicação foi pensada e apropriada pelo Estado. Diante disso, o modelo clássico de emissores e receptores, que leva a uma apreensão funcionalista e condutivista das relações sociais simbolicamente mediadas (SIGNATES, 2009), permeia o que podemos considerar como um modelo historicamente orientador das ações de comunicação desencadeadas pelo Estado que diante das mudanças no cenário político acabam por apresentar limitações.

EXTRAPRENSA (USP) - Ano V - no 09 dezembro/2011 


\section{Considerações finais}

Posicionar em uma perspectiva comunicacional crítica o informacionalismo - que norteia as ações comunicativas do Estado - é reconsiderar o campo da Comunicação Pública, em meio aos desafios de participação na democracia brasileira, a partir de questões centrais envolvendo os seguintes componentes:

a) Do ponto de vista normativo: refere-se a repensar a comunicação de mão única e organizá-la segundo uma perspectiva de interação cooperativa; avançar na democratização das políticas de comunicação e na ideia da Comunicação Pública como serviço a ser ofertado pelo Estado de forma a não restringi-la à comunicação governamental, sobretudo àquela atrelada à propaganda institucional dos governos e, por fim, fortalecer a ideia de que a Comunicação Pública saia dos domínios dos governos e seja assumida pelo Estado e a Sociedade.

b) Do ponto de vista operativo: exige-se equacionar déficits no que se refere à operacionalização da comunicação no âmbito das instituições públicas, sobretudo nos aspectos relativos à garantia do direito à informação e do direito à comunicação. A pretensão é consolidar políticas de comunicação que ofereçam garantias formais para circulação de informação, questão fundamental para o funcionamento dos espaços em que poder público é um ator chave;

c) Do ponto de vista político-conceitual: a demanda é consolidar a ideia de esfera pública ampliada superando seu escopo republicano que a encera como mero entorno do Estado, tendo a Comunicação Pública como campo capaz de organizar, hierarquizar e gerir simbolicamente essa esfera a partir dos princípios que a orientam como prática de comunicação singular.

\section{Referências Bibliográficas}

BRANDÃO. E. P. Conceito de comunicação pública. In: DUARTE, Jorge (org). Comunicação Pública - estado, mercado, sociedade e interesse público. São Paulo:Atlas, 2009, p. 01-33.

DAGNINO, Evelina (org). Sociedade Civil e Espaços Públicos no Brasil. São Paulo: Paz e Terra, 2002.

DUARTE, J. Instrumentos de comunicação Pública. In: DUARTE, Jorge (org). Comunicação Pública - estado, mercado, sociedade e interesse público. São Paulo: Atlas, 2009, p.59-71.

FAUSTO NETO, Antônio. Mudanças da Meduza? A enunciação midiatizada e sua incompletude. In: FAUSTO NETO, Antonio et al. (orgs). Midiatização e processos sociais na América Latina. São Paulo: Paulus, 2008, p.119-144.

EXTRAPRENSA (USP) - Ano V - no 09 dezembro/2011 
UMA PERSPECTIVA COMUNICACIONAL DA QUESTÃO DEMOCRÁTICA - TÓPICOS PARA O DEBATE SOBRE POLÍTICAS PÚBLICAS DE COMUNICAÇÃO

Transformações do campo jornalístico na sociedade midiatizada: as estratégias de celebração e consagração. In: MORAES, Dênis de. Mutação do visível - da comunicação de massa à comunicação em rede. Rio de Janeiro: Pão e Rosas, 2010. p.113-128.

HARVEY, David. A condição pós-moderna. Rio de Janeiro: José Olympio, 2000.

LOPES, Ruy Sardinha. Informação, Conhecimento e valor. São Paulo: Radical Livros, 2008.

MATTELART, Armand. História da Sociedade da Informação. São Paulo: Loyola, 2006.

MATOS, Heloiza. Comunicação Pública, Esfera Pública e Capital Social. In: DUARTE, Jorge (org). Comunicação Pública: Estado, Mercado, Sociedade e Interesse Público. $2^{\text {a }}$ ed. São Paulo: Atlas, 2009, p. 47-58.

PITTA, Aurea Maria da Rocha. Comunicação, Promoção da Saúde e Democracia: políticas e estratégias de comunicação no Sistema Único de Saúde no Brasil. 2001. Tese de doutorado. Programa de Pós-Graduação em Comunicação - Universidade Federal do Rio de Janeiro, 2001.

SANTOS, Boaventura de Sousa; AVRITZER, Leonardo. Para ampliar o cânone democrático. In: SANTOS, Boaventura de Sousa (org). Democratizar a democracia: os caminhos da democracia participativa. Rio de Janeiro: Civilização Brasileira, 2002.p.39-84.

SIGNATES, L. Comunicação como política pública: da abrangência teórica às questões políticas. Ser, Goiânia, v.1, n.1, p.4-19, jul./dez. 2009.

SODRÉ, Muniz. Eticidade, campo comunicacional e midiatização. In: MORAES, Dênis de (org). Sociedade Midiatizada. Rio de Janeiro: Mauad, 2006. p. 19-31.

Sobre a episteme comunicacional. Matrizes, São Paulo, n. 01, p.15-26, 01 out. 2007.

VIZER, E.A. La trama (in) visible de la vida social - comunicación, sentido y realidad. Buenos Aires: La Crujía, 2006.

. Movimentos sociais: novas tecnologias para novas militâncias. In: VICENTE, Maximiliano Martins (org.). Mídia e sociedade - perspectivas. Bauru: Canal 6, 2007, p.o9-30.

WOLTON, Dominique. É preciso salvar a comunicação. São Paulo: Paulus, 2006.

\section{Nota}

${ }^{1}$ Esse olhar compartilha do pensamento de Wolton (2006) de que qualquer teoria implícita ou explícita para pensar a comunicação remete a uma teoria da sociedade, ou seja, a uma representação das relações sociais, da cultura, da hierarquia, do poder (WOLTON, 2006, p. 126).

EXTRAPRENSA (USP) - Ano V - no 09

dezembro/2011 